\title{
EL TEATRO BREVE EN LOS INICIOS DEL SIGLO XXI
}

\author{
José ROMERA CASTILLO (ed.)
}

(Madrid: Visor Libros, 2011, 525 págs.)

Es impresionante la labor llevada a cabo, bajo la atenta y eficaz mano del Dr. José Romera Castillo, en el Centro de Semiótica Literaria, Teatral y Nuevas Tecnologías (el SELITEN@T), como puede verse en su página web: http://www.uned.es/centro-investigacion-SELITEN@T). Dentro de sus variadas líneas de investigación, relacionadas con la metodología semiótica, muy especialmente la de la escritura autobiográfica, las relaciones de la literatura y el teatro con las nuevas tecnologías, etc. — de las que su director ha sido pionero en España- destaca una, la dedicada al estudio del teatro (textos y representaciones), como ha establecido el profesor Romera en diversos y rigurosos estados de la cuestión, que, a continuación, reseño, para confirmar las palabras con las que abría este párrafo y que él mismo constata: «El estudio del teatro en el SELITEN@ @», en José Romera Castillo (ed.), El teatro de humor en los inicios del siglo XXI (Madrid: Visor Libros, 2010, págs. 9-48); «El teatro contemporáneo en la revista Signa dentro de las actividades del SELITEN@T», en José Romera Castillo (ed.), Teatro, prensa y nuevas tecnologías (1990-2003) (Madrid: Visor Libros, 2004, págs. 123-141); además de otros estudios parciales como «El teatro áureo español y el SELITEN@T», en Joaquín Álvarez Barrientos et alii (eds.), En buena compañía. Estudios en honor de Luciano García Lorenzo (Madrid: CSIC, 2009, 
págs. 601-610); «Una tesela más sobre investigaciones teatrales (siglos XVIII y XIX) en el SELITEN@T», en Homenaje al profesor Leonardo Romero Tobar (Zaragoza: Prensas Universitarias, en prensa); «Estudio de las dramaturgas en los Seminarios Internacionales del SELITEN@T y en la revista Signa. Una guía bibliográfica», en Manuel F. Vieites y Carlos Rodríguez (eds.), Teatrología. Nuevas perspectivas. Homenaje a Juan Antonio Hormigón (Ciudad Real: Ñaque, 2010, págs. 338-357); «Dramaturgos en los Seminarios Internacionales del SELITEN@T», Don Galán 1 (revista electrónica del Ministerio de Cultura) (2011): «Sobre teatro breve de hoy y el SELITEN@T», en José Romera Castillo (ed.), El teatro breve en los inicios del siglo XXI (Madrid: Visor Libros, 2011, págs. 7-24) y «Literatura, teatro y nuevas tecnologías: investigaciones en el SELITEN@T (España)», en Epos XXVI (2010), págs. 409-420 (que también puede leerse en http://congresosdelalengua.es/valparaiso/ponencias/lengua_comunicacion/romera_jose.ht $m)$.

Por lo que respecta a una de sus actividades más importantes, la celebración, anual, de un Seminario Internacional, bajo la esmerada dirección del profesor Romera Castillo, sobre aspectos relacionados con el estudio de la literatura y el teatro a finales del siglo XX y principios del XXI, indicaré que de los veintiún encuentros científicos, celebrados hasta el momento (2011), doce se han dedicado al examen de lo teatral en sus diversas facetas, cuyas Actas, editadas con rigor por el profesor Romera, y publicadas por la editorial madrileña Visor Libros, doy cuenta a continuación: Teatro histórico (1975-1998): textos y representaciones (1999), Del teatro al cine y la televisión en la segunda mitad del siglo XX (2002); Teatro y memoria en la segunda mitad del siglo XX (2003); Teatro, prensa y nuevas tecnologías (19902003) (2004); Dramaturgias femeninas en la segunda mitad del siglo XX: espacio y tiempo (Romera, ed., 2005) —un proyecto europeo, DRAMATURGAE, realizado conjuntamente, por iniciativa del profesor Romera, con las universidades de Toulouse-Le Mirail (Francia) y Giessen (Alemania)_; Tendencias escénicas al inicio del siglo XXI (2006); Análisis de espectáculos teatrales (2000-2006) (2007); Teatro, novela y cine en los inicios del siglo XXI (2008); El personaje teatral: la mujer en las dramaturgias masculinas en los inicios del siglo XXI (2009) — claro contrapunto del dedicado a las dramaturgias femeninas-; El teatro de humor en los inicios del siglo XXI (2010) y El teatro breve en los inicios del siglo XXI, cuyas Actas se reseñan aquí.

Pero antes de ello, destacaré que no es la primera vez que este Centro de Investigación se ocupa del estudio de los discursos breves, ya que el décimo 
de sus Seminarios Internacionales se dedicó a El cuento en la década de los noventa (Madrid: Visor Libros, 2001, 743 págs.), a cuyas Actas, editadas por los profesores José Romera Castillo y Francisco Gutiérrez Carbajo, remito.

Por lo que respecta al volumen, objeto de esta reseña, que recoge los resultados del vigésimo Seminario Internacional, El teatro breve en los inicios del siglo XXI — celebrado en Madrid, del 28 al 30 de junio de 2010, con la colaboración del Centro de Documentación Teatral (INAEM del Ministerio de Cultura) y del Instituto del Teatro de Madrid - es preciso constatar el pormenorizado trabajo de José Romera Castillo, «Sobre teatro breve de hoy y el SELITEN@T» (págs. 7-24), que abrió las sesiones de trabajo del encuentro, en el que se recogen todos los estudios llevados a cabo en el Centro sobre esta modalidad discursiva teatral.

El resto de las sesiones plenarias correspondió a destacados dramaturgos y críticos. Trataron de su práctica teatral, José Luis Alonso de Santos, «Mi teatro breve» (págs. 27.33); Antonia Bueno, «Breve reflexión sobre mi teatro breve: El otro (monólogo imposible) (págs. 35-43) —que adjunta una de sus piezas-; Jesús Campos, «Sintetizar la síntesis» (págs. 45-61); José Ramón Fernández, «Teatro breve como primer apunte y como trabajo en común. Algunas experiencias personales (2000-2010)» (págs. 63-77); Gustavo Montes, «La poética del teatro hurgente» [sic] — como él llama a su teatro breve — (págs. 93-102) y José Moreno Arenas, «Un teatro de urgencias» (págs. 103-120) —con un texto: Trilogía mínima de las pulgas de hotel- . Por su parte, Eduardo Quiles, en «Teatro corto, una vía para dominar la escritura teatral» (págs. 121-126), examina tanto su práctica de esta modalidad discursiva como la labor de la revista, que dirige, Art Teatral, centrada en esta tipología teatral. Así como dos autores más se suman a este coro, aunque en lugar de analizar su teatro, examinan otros aspectos generales como sucede con las intervenciones de Jerónimo López Mozo, en «El teatro breve, si bueno... (perspectivas: entre la obra de arte y el gag)» (págs. 127-155) y Roberto García de Mesa, en «La acción y la performance: dos modelos de teatro breve poético contemporáneo» (págs.7992). Una nómina de escritores muy representativa y significativa.

Varios críticos se detienen en el análisis del teatro breve. Además del profesor Romera, cuyo trabajo cité anteriormente, Francisco Gutiérrez Carbajo, en «Modalidades del teatro breve según su forma discursiva» (págs. 157177); Virtudes Serrano, en «Fragmentos de vida. Piezas breves de autora en el siglo XXI» (págs. 27-33) y Mariano de Paco, en «La confesión: textos para un espectáculo» (págs. 179-191). 
A continuación aparecen veintidós comunicaciones, que se publican tras previa selección, y que estudian diversas producciones tanto textuales como espectaculares en los inicios de nuestra centuria, encabezadas por la de María Jesús Orozco Vera, «Microteatro español y cine comprimido en el panorama cultural de la última década» (págs. 211-225).

Examinan obras y puestas en escena de dramaturgos Verónica Azcue, en «El corazón de Antígona, de Pati Doménech, tragedia en un acto» (págs. 241-254); Juana Escabias Toro, en «Acción dramática y teatralidad en la obra breve de Guillermo Heras» (págs. 255-262); Fernando Olaya Pérez, en «Prefiero que me quite el sueño Goya a que me lo quite cualquier hijo de puta, de Rodrigo García: el retorno a la palabra mediante la acción» (págs. 277288); Manuela Fox, en «El teatro breve de Jerónimo López Mozo» (págs. 299-313); Claire Spooner, en «Las obras breves de Juan Mayorga: ¿Metáforas visibles?» (págs. 315-331) y Simone Trecca, en «Buscando pasadizos: el Teatro para minutos, de Juan Mayorga» (págs. 333-348); Juan José Montijano Ruiz, en «Mihura por cuatro y la cara oculta de su retrato. El teatro breve surgido en torno al centenario de Miguel Mihura» (págs. 349-365); Carlos Sáinz-Pardo González, «Las dimensiones de lo breve en el teatro "indigesto" de José Moreno Arenas» (págs. 397-411), Susana Báez de Ayala, «Semiótica del silencio en Las pulgas dramáticas, de José Moreno Arenas» (págs. 367-381) y Francisco Linares Alés, «Metateatro en los textos breves (y brevísimos) de José Moreno Arenas» (págs. 383-396); Jorge Herreros Martínez, en «El teatro breve de José María Rodríguez Méndez: Espectáculo de calle del suburbio madrileño de estos tiempos» (págs. 413-424) y Federico Gaimari, en «Vacío y otras piezas breves del Teatro menor, de José Sanchis Sinisterra» (págs. 425-440).

Estudian piezas de dramaturgas, Lourdes Bueno, en «Lamento de mujer: problemas sociales en tres textos breves de Antonia Bueno» (págs. 227240); Rossana Fialdini Zambrano y Kay Sibbald, en «El "efecto de choque" en el teatro breve de Laila Ripoll» (págs. 263-275) y Ana Vidal Egea, en «Las Acciones en el teatro de Angélica Liddell» (págs. 289-297).

Se detienen en el estudio de otros aspectos tanto espectaculares como textuales Beatriz Villarino Martínez, en «Teatro breve y carnaval. Una apuesta innovadora de Chirigóticas» (págs. 441-453) y Carmen Itamad Cremades Romero, en «Brevedad: causa y efecto del minimalismo escénico en 60 obras de un minuto de 60 autores dramáticos andaluces» (págs. 455-467); Martín Bienvenido Fons Sastre, en «El teatro breve en la escena balear actual: los proyectos Història(es) y Seqüències» (págs. 469-483); Nerea Abur- 
to, en «Dibertimenduak de «Ez dok hiru» Bikoteatro: divertimentos lingüísticos en formato breve» (págs. 485-497); Gabriela Cordone, en «Poéticas del exilio en el teatro breve argentino» (págs. 499-512) y Alfredo Cerda Muños, en «Una perspectiva más de la frontera México-USA a través del teatro actual: Un año de silencio, de Rafael Martínez» (págs. 513-522).

En síntesis, nos encontramos en este volumen con el primer acercamiento a autores, obras y tendencias que articulan el teatro breve en la primera década del siglo XXI, que servirá sin duda para prolongar la historia de esta modalidad teatral, recogida en Javier Huerta Calvo (ed.), Historia del teatro breve en España (2008). Felicitaciones tanto al profesor José Romera, generador de tantas y tantas actividades de investigación propias y ajenas, como a todos los investigadores que han colaborado en este riguroso y esclarecedor volumen.

Laura Rivero 
